Educación Física y Ciencia, vol. 21, nº 1, e070, enero-marzo 2019. ISSN 2314-2561

Universidad Nacional de La Plata.

Facultad de Humanidades y Ciencias de la Educación.

Departamento de Educación Física

\title{
Ensino da dança na escola: enfrentamentos e barreiras a transpor
}

The teaching of dance at school: confrontations and barriers to overcome

\author{
Nilza Coqueiro Pires de Sousa \\ Universidade Estadual Paulista, Brasil \\ nilzacpsousa@yahoo.com.br
}

Dagmar Aparecida Cynthia França Hunger

Universidade Estadual Paulista, Brasil

dagmar.hunger@fc.unesp.br

\section{RESUMo:}

A dança é uma das mais tradicionais manifestações socioculturais presentes nas comunidades desde os primórdios da humanidade até os dias atuais. Não obstante, no contexto escolar, enfrenta muitos desafios no âmbito da docência e aprendizagem dos estudantes. Assim sendo, na presente pesquisa-ação, com um grupo de professores de Educação Física, Arte e Pedagogia, objetivou analisar os enfrentamentos e as barreiras a transpor, detectando as determinantes no processo de ensino e aprendizagem do ensino da dança na escola. A metodologia privilegiou a abordagem mista (quali-quantitativa), utilizando, para a coleta dos dados, o questionário, a entrevista semiestruturada e os relatos orais e escritos. Os resultados foram discutidos articuladamente na revisão da literatura, por intermédio de procedimentos estatísticos descritivos e da análise de conteúdo. Constatou-se: a) enfrentamentos internos: predomínio da escassez de materiais didático-pedagógicos e inadequada infraestrutura escolar; b) formação e conhecimentos científico-metodológicos: insuficiente preparação acadêmica e domínio do conteúdo em dança educativa e c) interferências externas: religião e mídia. Concluiu-se que urge uma revisão dos projetos político-pedagógicos e, consequentemente, uma tomada de decisão da equipe escolar para reconhecer o significado do ensino e da aprendizagem da dança na formação integral e diferenciada do educando.

Palavras-Chave: Educação básica, Professor escolar, Educação física, Arte, Pedagogia.

\section{Abstract:}

Dance is one of the most traditional socio-cultural manifestations present in the communities from the earliest days of humanity to the present days. Nonetheless, in the context of the education system, it faces many challenges in the scope of teaching and the student learning process. Thus, in the present action-research, with a group of Physical Education, Art and Pedagogy teachers, the aim was to analyze the confrontations and the barriers to overcome, detecting what is decisive in the teaching and learning process of teaching dance for school students. The methodology focused on the mixed (qualitative-quantitative) approach, using for data collection the questionnaire, semi-structured interview and oral and written reports. The results were discussed and articulated in the review of the literature, through descriptive statistical procedures and content analysis. It was verified: a) internal confrontations: predominance of the lack of didactic-pedagogical materials and inadequate school infrastructure; $b$ ) qualification and scientific-methodological knowledge: insufficient academic preparation and mastery of content in educational dance; and c) external interferences: religion and the media. It was concluded that a revision of the political-pedagogical projects and, consequently, a decision of the school team to recognize the meaning of the teaching and the learning process of dance in the integral and differentiated formation of the student is imperative.

KEYWORDS: Primary education, School teacher, Physical education, Art, Pedagogy.

\section{INTRODUÇÃo}

$\mathrm{Na}$ civilização humana a dança é uma das mais antigas manifestações socioculturais presente desde a antiguidade até os dias atuais. No entanto, no contexto escolar observa-se que a inserção da dança enfrenta ainda muitas dificuldades e acontece somente nos dias festivos, apesar de ser considerado componente obrigatório das áreas de Educação Física e de Arte. 
Documentos oficiais, como Parâmetros Curriculares Nacionais (PCN) (1997a, 1997b, 1997c), Referencial Curricular Nacional para a Educação Infantil (RCNEI) (1998), Diretrizes Curriculares Nacionais para a Educação Infantil (DCNEI) (Resolução, 2009), Diretrizes Curriculares Nacionais para o Ensino Fundamental de 9 (nove) anos (DCNEF) (Resolução,2010), Diretrizes Curriculares Nacionais Gerais da Educação Básica (DCNGEB) (2013) e Base Nacional Comum Curricular (BNCC) (2017), orientam o trabalho tanto dos professores de Pedagogia quanto dos docentes de Educação Física e de Arte com relação às diferentes linguagens, entre elas a dança.

Tais documentos esclarecem que, da educação infantil e do $1^{\circ}$ ao $5^{\circ}$ Anos do Ensino Fundamental, os componentes curriculares Educação Física (cultura corporal de movimento) e Arte (linguagens artísticas) poderão estar a cargo do professor de referência da turma, aquele com o qual os alunos permanecem a maior parte do período escolar, ou de professores licenciados nas respectivas áreas. Portanto, os três educadores, (Educação Física, Arte e Pedagogia), devem oportunizar vivências corporais e artísticas, de maneira interdisciplinar aos demais conteúdos do currículo, visando a formação integral dos alunos no desenvolvimento das múltiplas dimensões: cognitivo, motor, social e afetivo.

Contudo, na opinião de Marques (2011), tanto professores de Educação Física, educação infantil, professores formados em Pedagogia ou Arte, vêm trabalhando com dança nas escolas, sem que tenham sido realmente formados para isto, o que leva a um ensino precário e sem significado, pautado apenas na reprodução de técnicas didático-pedagógicas. A consequência disto é falta de espaço de criação, educação bancária (passiva), tecnicismo, falta de reflexão crítica etc.

No tocante ao ensino de Arte, Morandi (2006) lembra que essa disciplina tem alcançado cada vez mais espaço no âmbito escolar, embora depare com problemas metodológicos e conceituais, não conseguindo, ainda, proporcionar a equivalência de enfoque nas diversas linguagens artísticas.

Quanto à área da Pedagogia, nota-se que existe uma escassez, na literatura, a respeito da dança no ambiente escolar, tanto na formação inicial quanto continuada, destinada aos professores pedagogos da educação infantil e dos anos iniciais do ensino fundamental. Isso evidencia que raramente esses educadores ministram o conteúdo dança em suas aulas, apresentando uma lacuna na produção acadêmica dessa área de atuação.

Destaca-se, ainda, que nos últimos anos, pesquisas sobre o ensino da dança na escola têm abordado as seguintes dificuldades: material didático (Gaspari, 2005; Hunger et al., 2014; Peres, Ribeiro, \& Martins, 2001; Sousa, Hunger, \& Caramaschi, 2014), infraestrutura escolar (Gaspari, 2011; Saraiva, Fiamoncini, Abrão, \& Krischke, 2005; Sousa, Hunger, \& Caramaschi, 2014), preconceito (Böhm \& Toigo, 2012; Brasileiro, 2002; Saraiva-Kunz, 2003; Silva, Alves, \& Ribeiro, 2010), formação acadêmica (Gaspari, 2005; Peres, Ribeiro, \& Martins, 2001; Silva, Alves, \& Ribeiro, 2010; Sousa, Hunger, \& Caramaschi, 2014), questões religiosas (Hunger et al., 2014), midiáticas (Cunha, 2012; Gaspari, 2005; Hunger et al.,2014; Sgarbi, 2009), etc enfrentadas pelos docentes ao ministrar esse conteúdo em suas aulas. Contudo, majoritariamente, tais estudos foram realizados com apenas professores de Educação Física, sem questionar os professores das áreas de Arte e Pedagogia.

Desta maneira, considerando que as três áreas podem atuar com a dança na escola, a presente pesquisaação, por intermédio de um programa de formação continuada no âmbito da dança, focou a atenção para a formação e atuação de um grupo de professores, em relação ao corpo de conhecimentos educativos da dança, bem como, buscou-se a interdisciplinaridade e contribuir para melhorar o ensino da dança no contexto escolar, em todas as suas dimensões (corporal, cognitiva, afetiva, ética, estética, de relação interpessoal e inserção social), objetivando renovação da prática educativa e pedagógica do professor.

Neste sentido, com base nos documentos oficiais (BNCC, 2017; DCNGEB, 2013; PCN, 1997a, 1997b, 1997c; RCNEI, 1998; Resolução, 2009; Resolução, 2010), no posicionamento de Marques (2011), nas dificuldades apontadas na literatura para ministrar os conteúdos de dança no contexto escolar e no desenvolvimento do programa, questionamos inicialmente, o que pensam os professores sobre os enfrentamentos e as barreiras a transpor no âmbito do ensino da dança na escola? 
Entendemos que ouvir aqueles que diretamente estão envolvidos no processo de ensino-aprendizagem da dança na escola, possibilitará reflexões e discussões para o reconhecimento da dança e oferecerá oportunidades para todos os alunos vivenciarem suas descobertas e explorações corporais na escola, observando as possibilidades de construção de tempo e espaço educativos e de experiências em dança, particularmente com crianças.

Portanto, o objetivo deste estudo foi analisar os enfrentamentos e as barreiras a transpor por um grupo de professores de Educação Física, Arte e Pedagogia, detectando-se as determinantes no processo de ensino e aprendizagem do ensino da dança na escola.

Diante de tais apontamentos, justifica-se a relevância da presente pesquisa, inicialmente, pela constatação de lacunas na produção científica no campo educacional, referente ao ensino da dança na escola, voltada para as três áreas de atuação. Em segundo lugar, por verificar que a maioria das pesquisas acadêmicas, relacionadas à formação docente, centraliza-se na formação inicial e, por fim, para proporcionar aos professores dessas três áreas, em conjunto, um programa de formação continuada, destinado ao ensino e aprendizagem dos conteúdos da dança, alicerçado nos princípios da pesquisa-ação. Isto constitui um forte procedimento para a formação dos professores, devido à ação cooperativa implicada e ao trabalho em equipe, pelo qual os professores se orientam, corrigem, avaliam seus problemas e tomam decisões para melhorar, analisar e questionar a prática social e educativa (Imbernón, 2010), visando a elaboração do conhecimento científico sobre os sentidos do fazer profissional (Franco, 2005).

\section{MÉTodos}

\section{Tipo de estudo}

Conforme fundamentação teórica referente à pesquisa-ação, em que o processo teórico-metodológico da investigação escolar deve-se basear em atividades pedagógicas, na qual foram desenvolvidas ações presenciais fundamentadas, por intermédio de programa de formação continuada, atentando-se no movimento açãoreflexão-ação, isto é, na análise da prática concreta do professor, iluminada pela reflexão teórica e visando uma nova prática reelaborada (Thiollent, 2011). Por meio da análise de suas próprias práticas, os professores colaboradores, auxiliados pela pesquisadora e coordenadores do Programa, podiam refletir sobre suas ações e concretizá-las.

Imbernón (2010) preconiza que a pesquisa-ação pode influenciar o conhecimento dos professores e transformá-los em pesquisadores de si mesmos, incitando-os diretamente a reconstruir e a transformar sua prática diária e, além disso, teorizar e revisar continuamente seus processos educacionais. Optou-se, nesta investigação, a trabalhar com a pesquisa-ação, por ter-se a convicção de que pesquisa e ação podem e devem caminhar juntas, quando se pretende a transformação da prática (Franco, 2005).

O Programa de Formação Continuada em Educação Física, com foco na Dança e voltado para o ensino na escola, foi promovido entre 2013-2014, por uma Universidade Pública, em parceria com duas Secretarias Municipais e uma Diretoria Regional Estadual de Educação do interior de São Paulo. O Programa formou duas turmas, perfazendo três módulos, num total de 180 horas, durante um ano e meio e a carga horária de cada encontro totalizou 120 minutos.

Para nos referirmos aos participantes colaboradores dessa investigação, adotamos a denominação de professores. Com o intuito de facilitar a identificação, colocamos a sigla P para Professor, acrescida da sigla de cada área. Assim, para a área de Educação Física, colocamos a sigla PEF, para Arte, a sigla PA e para Pedagogia, a sigla PP, que foi subdivida em Educação Infantil (EI) e Ensino Fundamental (EF), na qual atribuímos nomes fictícios a todos os educadores da pesquisa. 


\section{Professores colaboradores do estudo}

Os colaboradores foram 41 educadores com formação em Educação Física, Arte e Pedagogia, atuantes na educação infantil e nos anos iniciais do ensino fundamental, sendo dez de Educação Física, dez de Arte e vinte e um de Pedagogia (oito da educação infantil e treze do $1^{\circ}$ ao $5^{\circ}$ anos do ensino fundamental).

As idades dos participantes desse grupo foram distribuídas em quatro categorias de 21 e 60 anos, sendo a média geral de 37 anos. $O$ participante mais jovem tinha 24 anos e o com mais idade, 59 anos. Notamos que 41\% (17) dos docentes encontram-se na faixa etária entre 21 a 30 anos; 24\% (10), entre 31 a 40; 15\% (6), entre 41 a 50 e $20 \%$ (8), entre 51 a 60 anos.

Verificamos que o grupo de PEF é formado por 60\% (6) de mulheres e 40\% (4) de homens. Já o de PA é constituído por $80 \%$ (8) de mulheres e $20 \%$ (2) de homens, enquanto que o grupo de PP é composto somente por mulheres.

Em relação à formação acadêmica, evidenciamos que todos os PEF e PA possuem formação superior na sua área de atuação. No grupo das PP, 71\% (15) possuem graduação na sua respectiva área de atuação, 14\% (6) também têm formação em outro curso superior e apenas $5 \%$ (2) possuem somente o curso Normal Superior.

Quanto à natureza da instituição de formação da graduação, constatamos que 61\% (25) dos docentes realizaram sua formação superior em instituições privadas, enquanto 39\% (16) dos participantes frequentaram instituições públicas, concluindo sua formação entre 2001 a 2012.

No que diz respeito à formação continuada, 78\% (32) dos PEF, PA e PP possuem pós-graduação com formação lato sensu (especialização) e 22\% (9) dos participantes não realizaram nenhuma especialização. Desse grupo, apenas 5\% (2) dos docentes, sendo uma PEF e uma PP possuem formação stricto sensu (mestrado), concluída ou em andamento. O período de realização da formação continuada, mencionado pelos PEF, PA e PP foi entre 1998 e 2013.

O tempo de experiência na docência variou de um ano a 38 anos, ou seja, contemplamos desde professores iniciantes a professores em fase de aposentadoria. Notamos que os educadores atuam na educação básica, nos níveis Maternal I e II, Jardim I e II da Educação Infantil, Anos Iniciais e Finais do Ensino Fundamental, Educação Especial, bem como uma coordenadora pedagógica e uma professora cedida a uma instituição de pessoas com deficiência e necessidades educacionais especiais.

\section{Procedimentos de coleta e análise dos dados}

Esta investigação caracterizou-se pela abordagem do tipo quantitativo e qualitativo (Bogdan \& Biklen, 2013), integrando métodos mistos na recolha e na análise dos dados. Este duplo recurso é encarado como um complemento ou uma integração e entendido como uma abordagem flexível, por meio de uma atitude colaborativa na pesquisa (Howe, 1988). O propósito da pesquisa de métodos mistos, conforme Johnson, Onwegbuzie e Turner (2007), é o de ampliar e aprofundar o conhecimento e sua corroboração.

Para a realização desta investigação, o projeto de pesquisa obteve a aprovação do Comitê de Ética da Universidade Estadual Paulista “Júlio de Mesquita Filho" (Processo n 13076/46/01/12), em que todos os participantes receberam as informações necessárias para a participação na pesquisa e autorizaram a utilização dos dados mediante a assinatura do termo de Consentimento Livre e Esclarecido (TCLE).

Assim, para o desenvolvimento das etapas desta pesquisa-ação, foram definidas, como estratégias de coleta dos dados empíricos, as seguintes técnicas: questionário, entrevista semiestruturada, relatos orais e escritos. Ao escolher essas estratégias, procuramos utilizar diferentes métodos e técnicas, para assegurar uma profunda compreensão do fenômeno em questão (Denzin \& Lincoln, 2006).

Os procedimentos de análise e discussão dos resultados foram discutidos articuladamente na revisão da literatura, por intermédio do tratamento estatístico descritivo (Gil, 2009) e da técnica de análise de conteúdo 
para os dados qualitativos, de acordo com as premissas de Bardin (2016), sendo realizado com auxílio do software QSRNVivo, versão10. Com a triangulação desses dados gerados pelas diferentes fontes de coleta, temos as categorias de análises: enfrentamentos internos; formação e conhecimentos cientifico-metodológicos e interferências externas.

\section{Resultados e Discussão}

Os enfrentamentos das PEF, PA e PP para ministrar os conteúdos de dança foram agrupados em três categorias: a) enfrentamentos internos; b) formação e conbecimentos cientifico-metodológicos e c) interferências externas. OGráfico 1 apresenta as respostas determinantes pelas três áreas de atuação, sendo que alguns professores abordaram mais de um problema.

No Gráfico 1, constatamos que o problema predominante, destacada pelas três áreas de atuação, foi relacionado aos enfrentamentos internos (materiais didático-pedagógicos, a infraestrutura escolar, a equipe escolar e a resistência dos alunos), totalizando 58\% (84) das respostas. Em seguida, com 24\% (35) de indicações, os professores relacionaram problemas da formação e dos conhecimentos científico-metodológicos (falta de capacitação, ao conhecimento específico em dança e ao domínio do procedimento didáticopedagógico) e, em 18\% (27) das ocorrências, associaram tais dificuldades às interferências externas (religião e mídia).

\section{Gráfico 1}

Enfrentamentos em ministrar as aulas de dança na escola, relatadas pelosprofessores de Educação Física, Arte e Pedagogia.

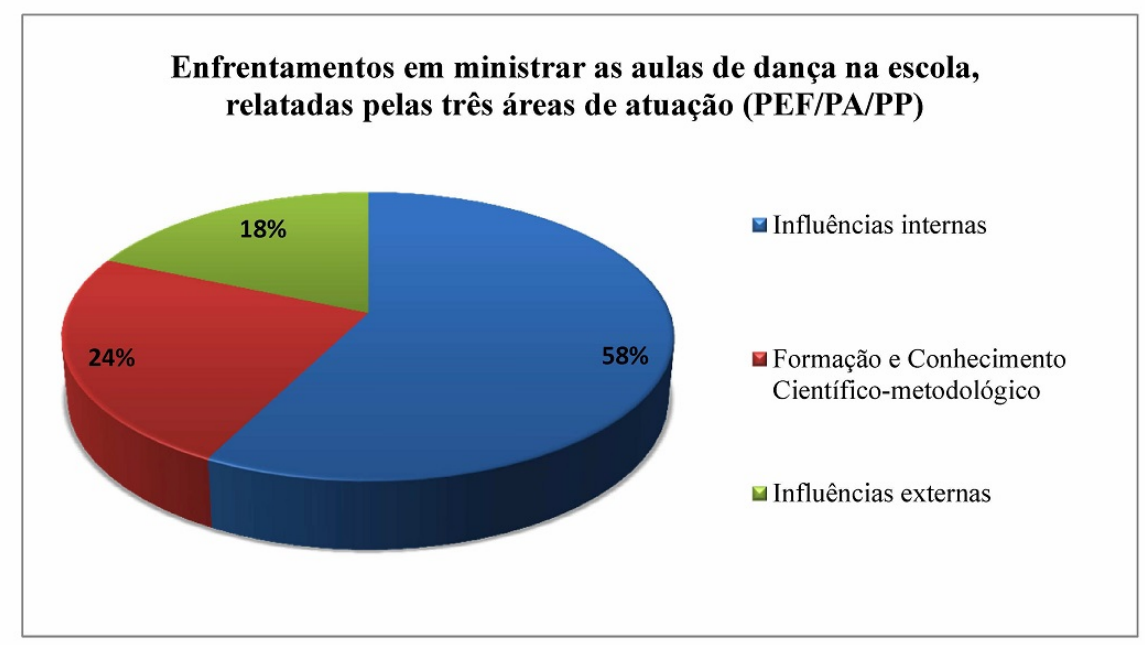

Nossos resultados são confirmados pelos estudos realizados nos últimos anos por vários pesquisadores, que desenvolveram suas pesquisas com professores de Educação Física (Böhm \& Toigo, 2012; Gaspari, 2005; Peres, Ribeiro, \& Martins, 2001; Silva, Alves, \& Ribeiro, 2010), de Arte (Cunha, 2012), de Pedagogia voltada à educação infantil (Hunger et al., 2014; Sgarbi, 2009) e conjuntamente com docentes de Educação Física e Arte (Sousa, Hunger \& Caramaschi, 2014), sempre relacionadas ao ensino da dança na escola. 


\section{a) Dos enfrentamentos internos}

$\mathrm{Na}$ categoria enfrentamentos internos, em $58 \%$ (84) do total das manifestações dos professores, verificadas no Gráfico 1, constatamos que 25\% (37) são referentes aos materiais didático-pedagógicos; em 22\% (32), à infraestrutura escolar; em 8\% (10), à equipe escolar e em 3\% (5), à resistência do aluno.

Osmateriais didático-pedagógicos $(25 \%$; 37$)$ foram o principal ponto elencado pelos professores das três áreas de atuação, a respeito dos enfrentamentos internos. Dentre eles, destacam-se as indicações referentes aos recursos didáticos audiovisuais (aparelho de som, televisão, DVDs, CDs, data show, informática, sala de multimídia, vídeos, microfone, etc.) e aos recursos pedagógicos (livros, filmes, artigos, documentários, entre outros).

A ausência de materiais pedagógicos, tanto para os professores quanto para os alunos, pode ser constatado no relato da PEF Carmem, enfatizando que "na escola não tem materialpedagógico de dança". Já o depoimento da PP (EF) Natascha ressalta a necessidade de solicitar o material com antecedência "se solicitados com antecedência de mais ou menos doismeses e se cobrarmos bastante até conseguirmos o material".

Os resultados revelam a escassez dos materiais didático-pedagógicos na escola, bem como a burocracia para ter acesso aos materiais necessários para a realização de aulas voltadas para a dança, o que dá indícios da pouca importância atribuída a esse conteúdo pela equipe gestora e órgãos públicos. A PP (EF) Martha, a PP (EF) Olga e a PA Victória preferem levar o seu próprio aparelho sonoro e materiais para viabilizar o acesso à informação e desenvolver esse conteúdo para as suas turmas.

Semelhantemente às nossas evidências, os estudos de Gaspari (2005), Peres, Ribeiro e Martins (2001) e Sousa, Hunger e Caramaschi (2014) também identificaram as dificuldades dos docentes, referentes aos materiais didático-pedagógicos adequados nas escolas.

Os educadores da nossa pesquisa apontaram a falta de recursos pedagógicos (livros, filmes, artigos, documentários, entre outros) voltados aos conteúdos de dança na escola, o que vai de encontro à pesquisa de Gaspari (2005), na qual as participantes reclamam da ausência de publicações de livros didáticos que possam dar um norte e guiar o trabalho com a dança.

No entanto, a pesquisa de Sousa, Hunger e Caramaschi (2014), com 64 professores efetivos de Educação Física (31) e de Arte (33), que atuam do $1^{\circ}$ ao $5^{\circ}$ anos do ensino fundamental, da rede pública estadual e municipal de uma cidade do interior do estado de São Paulo, verificou que a questão do material de apoio das escolas foram as limitações e dificuldades mais sentidas pelos educadores de Arte (43\%), divergindo de nossas evidências nesse aspecto.

Desse universo de professores, somente a PEF Alice e a PEF Cecília relataram a chegada de alguns livros excelentes para a área de Educação Física, nas escolas públicas estaduais. A fala da PEF Alice demonstra o seu entusiasmo para com esse recurso pedagógico: "eu achei interessante quechegou agora de $1^{\circ}$ ao $5^{\circ}$ anos, que a gente também pode estar trabalhando e, não só as professoras de sala. Chegaram muitos livros africanos".

Do mesmo modo que no estudo de Sousa, Hunger e Caramaschi (2014), observamos que a maioria das escolas não oferece material pedagógico para subsidiar a prática pedagógica docente. Porém, os autores ressaltam a necessidade de proporcionar momentos de discussões e reflexões, com a participação de toda a equipe escolar, a respeito da aquisição e compartilhamento de materiais didático-pedagógicos, a fim de encontrar solução para amenizar o problema e tornar possível o ensino significativo da dança na escola.

Peres, Ribeiro e Martins (2001) consideram importante lutar contra essa dificuldade, sugerindo que os professores busquem auxílio em cursos, livros e outras bibliografias, além de desenvolver estratégias, utilizando a criatividade pessoal para realizar atividades que levem à construção do conhecimento de dança. Concordamos com os autores e acreditamos que as secretarias municipais e estaduais devem investir mais nessa área específica, para garantir um acervo didático-pedagógico com livre acesso dos professores e alunos, bem como da comunidade escolar. 
Diniz e Darido (2012) propõem algumas reflexões sobre como o livro didático se articula com a Educação Física, apontando discussões sobre o processo deelaboração de um material de dança, na perspectiva da Pluralidade Cultural, tanto para o professor quanto para o aluno, defendendo-o como um recurso que possa complementar o processo de ensino-aprendizagem de maneira construtiva e enriquecedora, que estimule a criatividade dos alunos e, principalmente, garanta a autonomia do professor, fornecendo subsídios para que ele consiga abordar os conteúdos de dança na escola, bem como contribua para a sua prática pedagógica.

A infraestrutura escolar $(22 \% ; 32)$ foi a segunda barreira indicada pelos participantes das três áreas de atuação, no tocante aos enfrentamentos internos. Verificamos que são os PA e as PP que mais sentem a falta de espaço adequado para as aulas de dança. Das indicações sobre a infraestrutura escolar, evidenciamos três tipos de problemas: limitação do espaço, estrutura física inadequada e falta de espaço físico, como evidenciam os discursos a seguir, referentes a essas dificuldades.

Quanto à limitação do espaço, a PA Johana relatou que "a escola é pequena, tempouco espaço físico, não tem quadra próxima à escola, salas muito apertadas, com muitos alunos, inclusive alunos especiais que necessitam de atenção contínua do professor". No quese refere à infraestrutura escolar inadequada, o discurso da PP (EI) Isadora demonstra que "oespaço não é ideal, porque estão instaladas provisoriamente em um salão paroquial, porque a escola está sendo reconstruida". Já a falta do espaço físico é exemplificado pela PP (EF)Fanny, ressaltando que "não há espaço para danças e brincadeiras, pois até nossa quadra édividida entre a escola de ensino fundamental 1 com a EF2, portanto, o uso é dos professores de educação física e não há tempo para agendamento para pedagogos".

As pesquisas de Gaspari (2011), Saraiva et al. (2005) e Sousa, Hunger e Caramaschi (2014) confirmam os nossos resultados quanto à pouca estrutura, espaço adequado e falta de instalações nas unidades escolares. O que a nossa pesquisa diferencia, em relação a esses estudos, é a inclusão das PP. Parece que os espaços, tanto para os PA quanto para as PP, se restringem à sala de aula. Assim, quando tentam realizar um trabalho diferenciado, sentem essa resistência, uma vez que a quadra geralmente é destinada para os PEF.

Os prédios escolares representam instituições baseadas em velhos paradigmas, que parecem ter parado no tempo e apresentam problemas em relação à funcionalidade, falta de adequação entre atividades e seus espaços, acessibilidade, acústica, ambientes adequados para a socialização, entre outros.

Se, por um lado, os PA e as PP têm pouco ou não têm espaço, por outro, a questão do espaço da aula para os PEF, no que se refere ao conteúdo de dança, parece ser uma polêmica, de acordo com Gaspari (2011), especialmente no que se refere à necessidade de uma sala própria para as aulas de dança e à falta de um espaço específico, considerado ideal. A autora acredita que poderiam ser aproveitados todos os espaços possíveis da escola, proporcionando aos alunos a oportunidade de dançarem em diferentes lugares, experimentando espaços pequenos, médios e grandes.

Nessa mesma linha de pensamento, Saraiva et al. (2005) sugerem a utilização de diferentes espaços, onde a dança pode ser vivenciada em locais como quadras e bosques, que se transformam em cenários e que suscitam diferentes questionamentos em relação à necessidade de um espaço "ideal” para a dança. As autoras acreditam que se trata de uma reflexão importante, que auxilia no momento do planejamento e da organização da dança, de acordo com os espaços disponíveis da escola.

Sousa, Hunger e Caramaschi (2014) enfatizam que, para amenizar essa problemática, faz-se necessário pensar na reestruturação física por toda a equipe escolar. Acreditamos que essa questão não cabe só ao docente, mas é preciso toda uma organização espacial e temporal a ser discutida, pensada e refletida por todos os envolvidos com o processo educativo, para que os professores, independentes da área de atuação, possam usufruir dos espaços disponíveis na escola, para conseguirem ministrar os vários conteúdos do currículo.

As ocorrências sobre a equipe escolar $(8 \% ; 10)$, foram referenciadas pelos docentes das três áreas, no que se refere aos enfrentamentos internos, sendo a terceira barreira mais citada. Os depoimentos apontaram que a gestão escolar não apoia as atividades diferenciadas. Dentre os motivos, estão: querem a sala quieta e que o aluno tenha o caderno preenchido. Além disso, existe a falta de uma melhor concepção de dança por parte dos 
demais professores da escola. Marques (2012, p. 23) assinala que a "dança na escola tem como compromisso social ampliar o escopo, a visão e as vivências corporais do aluno em sociedade, a ponto de torná-lo um sujeito criador-pensante [grifo da autora] de posse de uma linguagem artística transformadora".

O PA Juan considera que "essa interferência é muito danosa, principalmente na nossaárea" e aPP (EF) Roxane manifesta que "a secretaria sabe que a gente vem aqui, mas falta apoiar em relação à escola. Apoiar, deixar a gente vir aqui é uma coisa. Agora chegar na sala de aula e fazer é outra".

Nossos resultados são semelhantes aos da pesquisa realizada por Gaspari et al. (2006), que constatou que a falta de apoio da direção, supervisão e coordenação escolar foi uma das dificuldades relatadas pelos 21 professores de Educação Física que atuam no ensino fundamental e médio da rede pública ou privada dos estados de São Paulo e Minas Gerais, bem como aos do estudo realizado por Lessa e Lima (2014), com 28 professores de Educação Física das escolas municipais da cidade de Canindé-CE.

Essas evidências levam-nos a refletir sobre o que enfatiza Mizukami e Reali (2002), em relação à necessidade de minimizar o distanciamento nas relações entre os docentes e a direção escolar, numa tentativa de realização de um trabalho efetivamente conjunto, ou seja, através da construção de ações coletivas. As autoras ressaltam que para a Educação Física, faz-se ainda mais importante tal aproximação.

Contudo, salientamos que é fundamental a aproximação também com os PA e as PP, no tocante ao ensino da dança.

A dança sempre esteve pouco presente nas escolas, apesar do ensino de Arte e de Educação Física, alcançar cada vez mais espaço no âmbito escolar. Morandi (2006) enfatiza que a dança, além de se deparar com problemas metodológicos e conceituais (formação inicial, predominância das artes visuais e dos esportes, falta de diversificação de conteúdos, falta de aprofundamento, etc.), ainda não conseguiu proporcionar equivalência de enfoque nas diversas possibilidades dos conteúdos dessas duas áreas.

A inserção da dança no ambiente escolar enfrenta ainda muitas dificuldades. Embora faça parte dos documentos norteadores da educação básica, como um dos conteúdos a serem trabalhados nas aulas regulares das respectivas disciplinas e considerados componente obrigatório nos diversos níveis de ensino, acontece raramente nas escolas e somente nos dias festivos, com a finalidade única de apresentar espetáculo.

Brasileiro (2008) ressalta que Arte e Educação Física têm, hoje, em comum, a dança, no seu universo de conhecimentos identificadores. No entanto, a dança que se apresenta no interior dos dois cursos de formação, acrescentando também a graduação em Pedagogia, é cada dia menos vista nos processos de formação escolar básica no Brasil.

Para Strazzacappa e Morandi (2006), a maioria dos estudos referentes ao ensino da Arte, concentra-se basicamente no campo das artes visuais (Morandi, 2006) e da Educação Física, no campo das modalidades esportivas (Gaspari, 2005; Morandi, 2006, Pereira, 2007). Como nesses campos o ensino já vem se processando há mais tempo, os problemas referentes ao processo educacional despertam ampla discussão e reflexão, o que não acontece com a dança. Dessa maneira, a dança ainda tem um longo caminho a percorrer, lutando para se estabelecer e os professores dispostos a enfrentar os problemas que surgirão quando esse conteúdo estiver efetivamente inserido no contexto escolar.

Gasparelo, Kronbauer e Gomes (2018) ressaltam que das aproximações encontradas entre a Arte e a Educação Física, acreditam que a dança pode ser um importante elemento de articulação entre essas áreas, uma vez que estão na área de conhecimento de linguagens na BNCC (2017). As autoras salientam quetornase imprescindível usar a interdisciplinaridade como possibilidade de interlocução das áreas em torno da dança a fim de apresentar um conteúdo consistente e edificante para a construção do conhecimento dos alunos, e ampliar as forças e a representatividade da dança dentro e fora do ambiente escolar.

Concordamos com as autoras, quando enfatizam que "a dança não deveria ser objeto de disputas de território entre áreas afins dentro da escola, mas sim um conteúdo que aproximasse as áreas em torno da finalidade maior da educação, reconhecendo sua multiplicidade e sua importância na formação de sujeitos 
críticos, autônomos e protagonistas de uma sociedade mais justa” (Gasparelo, Kronbauer \& Gomes, 2018, p. 48).

Os PA participantes da presente pesquisa-ação possuem formação em Educação Artística, com habilitação em Artes Plásticas,Artes Cênicas e Música. Nenhum especificamente em dança, no entanto, constatamos a preocupação desses docentes com o impacto do ensino da dança na escola como uma prática artística articulando com educadores de outras áreas como Educação Física e Pedagogia. Por isso, ingressaram nesse programa de formação continuada em educação física, com foco na dança.

Dentre os motivos elencados, o PA Marius, em seurelato, afirmou que pretende "melhorar a forma como trabalho com essa área artística", além de ressaltarque "a troca de experiências é importante porque as vezes nos falta um outro olhar e no meucaso consegui isso através do curso". Jáa PA Johana enfatizou que "não tive um embasamento teórico-prático suficiente para ministrar a dança e por conta da mudança dagrade curricular, foi por conta de artes ter que trabalhar com dança, música e teatro, por conta da proposta do estado", do mesmo modo como respondeu a PAVictoria ao "querer cumprir com o curriculo". Enquantoa PA Guilhermina mencionou que "aplicava a dança, mas com dificuldade e sem segurança também. Então gostaria de ter segurança para estar atuando nessa área".

Podemos perceber que está acontecendo uma mudança no olhar dos educadores, especialmente no dos PA, que possuem formações específicas, como Artes Plásticas, Artes Cênicas e Música, ao buscar conhecimento nas linguagens artísticas, em que não possui muita vivência.

Os dados evidenciados confirmam os estudos de vários pesquisadores (Barreto, 2004; Marques, 2012; Morandi, 2006; Rossi, 2013; Sborquia \& Galhardo, 2002; Scarpato, 2004) sobre essa lacuna na formação inicial, bem como convergem para as expectativas relatadas na avaliação diagnóstica realizada no início do programa. Os educadores ressaltaram que investiram nessa formação por admitirem fragilidades nas suas formações e esperavam que essa ação formativa fosse capaz de colaborar para superar as dificuldades de trabalhar com a dança na escola.

Acreditamos que programas de formação continuada devem atender as necessidades de encontrar novas possibilidades para a prática docente, com sugestões de como trabalhar os conteúdos e, neste caso, a dança, de forma significativa, crítica e contextualizada.

A dificuldade sobre a resistência dos alunos $(8 \% ; 10)$, obteve uma menor incidência das respostas, no que se refere à categoria enfrentamentos internos. Verificamos que essa dificuldade foi apontada somente pelos PEF e PA, principalmente no que diz respeito ao preconceito dos alunos do sexo masculino. A PEF Milena argumenta que "a falta de costume para essa prática, dificulta a aula e por haverpreconceito por parte dos meninos".

Esses resultados são corroborados por várias pesquisas (Böhm \&Toigo, 2012; Brasileiro, 2002; SaraivaKunz, 2003; Silva, Alves, \& Ribeiro, 2010), que também constataram que uma das dificuldades dos professores de Educação Física refere-se ao preconceito, relacionado ao gênero, especialmente pelos meninos, por questões que envolvem a sexualidade (machismo), vergonha e inibição em relação ao conteúdo de dança.

Para Brasileiro (2002), essa polêmica é uma das razões da ausência do ensino sistemático de dança. Já Saraiva-Kunz (2003) analisou a relação de gênero através da dança e outras atividades expressivas, propondo conteúdos formativo e performativo para ambos os sexos, na escola, para estimular possibilidades de interação entre meninos e meninas.

A autora enfatizou que o potencial da educação estética de ampliar capacidades, experiências e conhecimentos em relação à dança e ao gênero pode ser realizado através de "propostas pedagógicas e didáticas que respeitem a forma de cada pessoa ser e viver no mundo[grifo da autora]" (Saraiva-Kunz, 2004, p. 144).

Segundo Marques (2011), falar de preconceitos pode parecer coisa do passado, já que o ensino de dança ainda está recoberto de ideias preconceituosas, em relação à sua natureza e esse fato leva muitos professores a atribuírem outras denominações às atividades de dança, como "expressão corporal”, "arte e criação" e "movimento e criação". Por isso, a autora ressalta a necessidade de discutir e refletir com os próprios alunos 
sobre esse aspecto, para que aos poucos a situação seja amenizada e os alunos percebam que dançar não é "coisa de mulher".

Silva, Alves e Ribeiro (2010) enfatizam que o professor deve contornar essas questões, pois é papel do professor resgatar seu aluno, ajudando-o se expressar e superar tais dificuldades. Já Castro, Silva e Júlio (2010) salientam que devemos rever nossos valores culturais, de forma que se evidenciem políticas de estímulo à aprendizagem e apreciação da dança, para melhorar a visão sobre o referido conteúdo e para que não haja preconceito com relação à dança.

Por isso, Saraiva e Fiamoncini (2013, p. 95) acreditamque

[...] a co-educação como uma prática conjunta de meninas e meninos, que propicia as mesmas vivências de movimento para ambos na aula de Educação Física. Essa prática está fundamentada, entre outras razões, na compreensão de que o movimento não tem sexo, e de que a discriminação tradicional de movimentos para homens e mulheres é construída no processo de socialização das pessoas, sendo, portanto, atrelada a visões/ valores culturais.

Böhm e Toigo (2012) destacam que os resultados da sua pesquisa deixaram claro que as dificuldades atuais existentes nas escolas ainda são as mesmas do passado, ou seja, apesar de toda a mudança de comportamento presente nessa geração, ainda permanecem padrões de valores ultrapassados e equivocados, em relação às atividades que envolvem o corpo e a arte.

Em síntese, verifica-se que dentre os enfrentamentos internos, os materiais didático-pedagógicos são as dificuldades predominantes, enfatizadas principalmente pelos PEF e PP. Em seguida, os educadores sugerem que a infraestrutura das escolas é limitada e inadequada, constatando que são poucas as escolas que oferecem uma estrutura com condições para a realização das aulas. Os PA e as PP são os que possuem mais dificuldades em encontrar um espaço para práticas de outras naturezas e, no caso do nosso estudo, da dança, ficando disponível somente à própria sala de aula.

Em menor incidência, os PEF e os PA são os que apresentam mais dificuldades relacionadas com a equipe escolar e com a resistência dos alunos. Podemos inferir, por essa evidência, que são esses educadores que estariam ministrando os conteúdos de dança em suas aulas, tendo que lidar com as questóes de reconhecimento e gênero, durante as aulas de dança.

\section{b) Daformação e dos conhecimentos científico-metodológicos}

Em relação à categoria formação e conhecimentos cientifico-metodológicos (Gráfico 1), que obteve 24\% (35) das indicações mencionadas pelos docentes das três áreas de atuação, destacaram-se, entre as dificuldades, a falta de capacitação $(9 \% ; 13)$, o conhecimento específico de dança $(8 \% ; 12)$ e os procedimentos didáticopedagógicos $(7 \% ; 10)$, observamos que foram as PP que mais mencionaram essas dificuldades.

No tocante à falta de capacitação, a PP (EF) Mora argumenta que "existe muitadificuldade para ministrar os conteúdos de dança, principalmente por falta de capacitação dos professores". Em relação ao conbecimento especifico de dança, a PP (EI) Gabriele relatouque "não sei direito quais são os conteúdos de dança". O domínio dos procedimentos didático-pedagógicos, principalmente a falta de tempo e a gestão de aula, foi apontado pelaPP (EF) Odete "como trabalho com conteúdos diversos, não sobra muito tempo para a dança,gostaria de ter tempo".

Em nosso estudo, os docentes consideraram a falta de formação e a ausência de conhecimentos científicometodológicos, como uma das dificuldades para ministrar a dança nas suas aulas, sendo esta também uma constatação presente na literatura consultada, de acordo com os professores de Educação Física (Gaspari, 2005; Peres, Ribeiro, \& Martins, 2001; Sousa, Hunger, \& Caramaschi, 2010), de Arte (Cunha, 2012; Marques, 2011) e de Pedagogia (Marques, 2011; Hunger et al., 2014; Sgarbi, 2009). 
Os estudos de Gaspari (2005), Sgarbi (2009) e Sousa, Hunger e Caramaschi (2010) evidenciaram que a pouca ou nenhuma experiência ou vivência com a dança e a formação inadequada do professor, dificultavam ministrar tal conteúdo na escola.

Cunha (2012) menciona que muitos professores de Arte sentem-se inseguros ao planejar suas aulas, devido aos resquícios de uma formação escolar tradicionalista, às lacunas no aprendizado de Arte, durante o curso de graduação e à falta de especialização. Tal insegurança e a inexperiência teórico-prática influenciam na postura dos mesmos, o que acarreta em aulas pouco motivadoras, que não ultrapassam os cadernos.

Corroborando nossos resultados, Marques (2011) afirma que, na grande maioria dos casos, os professores não sabem exatamente o que, como ou até mesmo porque ensinar a dança na escola. A autora também enfatiza que os professores de Arte, Educação Física e Pedagogos do ensino infantil e fundamental $\left(1^{\circ}\right.$ ao $5^{\circ}$ anos) poderiam até trabalhar a dança na escola, mas não têm segurança para isso.

Cabe destacar que o conhecimento das proposições sobre a dança, nos documentos oficiais (BNCC, 2017, DCNGEB, 2013; PCN, 1997a, 1997b, 1997c ; RCNEI, 1998; Resolução, 2009; Resolução, 2010), é uma estratégia para amenizar essas barreiras, porque incentiva estudos com o envolvimento dos docentes, juntamente com toda equipe escolar. Ao se debruçarem para discutir, refletir, selecionar e organizar os conteúdos de dança, compatíveis com as possibilidades de aprendizagem dos alunos, respeitando as especificidades de cada área, os professores contribuem para a construção de um trabalho educacional. Esperase, com isto, que os resultados fluam naturalmente, originando, assim, um bom trabalho dentro do contexto onde estiver inserido.

De forma sintética, verificamos que as PP mencionam sentir mais dificuldades relacionadas à formação e aos conhecimentos científico-metodológicos, o que revela lacunas no curso de Pedagogia, no tocante ao conteúdo de dança.

\section{c) Das interferências externas}

As interferências externas, com 18\% (27) das ocorrências verificadas no Gráfico 1, estão relacionadas com a religião, conforme relatado por $10 \%$ (14) dos docentes, enquanto que a mídia foi indicada por $8 \%$ (13) dos participantes das três áreas de atuação.

A religião $(10 \% ; 14)$, segundo os depoimentos desses docentes, interfere na prática pedagógica, porque os pais não permitem a participação do aluno em nenhuma manifestação, principalmente, em festas juninas ou em aulas que envolvam dança. Algumas escolas optaram por não realizar mais tais festas, por conta dessa interferência. A PP (EF) Martha argumenta que essa é uma dificuldade que "interfere muito. Algumas crianças não participam de algunseventos por causa da religião".

A pesquisa de Hunger et al. (2014) verificou que a religião foi considerada um fator muito importante dentre as interferências externas, conforme relatos das professoras que atuam na educação infantil. De certa maneira, percebemos que a influência modifica a cultura escolar, pois o professor e a equipe escolar acabam tomando decisões radicais para enfrentar tais adversidades. Segundo Hunger et al. (2014), é preciso dialogar com todos os envolvidos, na tentativa de encontrar possíveis soluções para o impasse, uma vez que o maior prejudicado é o aluno, que fica impossibilitado de participar de novas vivências e, a partir dessas experimentações, fazer as suas escolhas.

No que tange às dificuldades associadas com as questões midiáticas $(8 \% ; 13)$, verificamos, que as três áreas de atuação sofrem interferências. Os professores argumentam que as músicas que os alunos ouvem e as danças que assistem têm bastante influência. Eles levam isso para a escola e não se interessam por outras músicas e danças.

Para o PA Juan, a mídia apresenta "a dança de forma inadequada e deturpada. [...] Ela é usada no sentido pejorativo, apelo sexual ou ligada à bebida. [...] Eu acho que esse é o efeito da mídia, desastroso. [...] É difícil combater esse poderoso meio de comunicação". Sborquia e Gallardo (2002) enfatizam que o recurso de utilizar 
dançarinas, adotado por vários cantores e grupos musicais, leva as crianças a uma visão mercantilizada, deturpada e prostituída da dança.

Complementando, a PEF Alice enfatizou que "essa parte é complicada, porque paraeles o que é o bom, é a música que está na mídia. Porque por eles só escutam o funk”. Corroborando esse relato, Correia (2006) salienta que a televisão é atualmente um importante formador de opinião, influenciando diretamente no comportamento e atitudes dos alunos. Essa rápida influência está muito evidente em relação à dança. $\mathrm{O}$ autor ressalta que quando a dança é trabalhada de forma descontextualizada e acrítica, perde o seu valor cultural, estético e expressivo e vira um simples entretenimento.

Confirmando os depoimentos dos docentes da nossa pesquisa sobre a influência da mídia nas aulas de dança, o estudo de Gaspari (2005) ressalta que a maior preocupação dos participantes foi quanto aos modelos de danças da mídia ou modismos, uma vez que os alunos confundiam a aula de Educação Física com a reprodução coreográfica (Marques, 2012; Sborquia \& Gallardo, 2002). Complementando esse aspecto, Strazzacappa (2003, p. 77) enfatiza que "é quase impossível evitar a interferência da mídia na escola, mas isso pode acontecer na hora do recreio e no intervalo das aulas, não como proposta de ensino de dança”.

Gaspari (2005) enfatiza que a mídia pode repercutir na criança e no adolescente sob dois pontos de vista: positivamente, se olharmos pelo lado de que eles já chegam à escola com desenvoltura e desinibição, cabendo ao professor saber aproveitar essas qualidades já desenvolvidas. Por outro lado, pode haver um aspecto negativo, porque a criança só aprende a repetir e reproduzir os movimentos, o que pode limitar a formação da criatividade.

Entretanto, a PA Geraldine ressaltou que "está na hora de mostrar o outro lado dadança. Os alunos não tem conhecimento de outros estilos de dança. [...] É só aquilo que eles veem na mídia. Se for proposta uma atividade diferente, eu acho que eles vão fazer, vão participar e vão conbecer novas coisas. Eu acredito que não terá resistência".

Em concordância com Correia (2006), ao enfatizar que a dança que a mídia leva para a escola acriticamente torna-se responsabilidade dos professores de Educação Física, que geralmente trabalha o conteúdo em suas aulas, acrescentamos também que essa discussão seja realizada por todos os docentes da escola. Afinal, o papel do professor é revelar essa irresponsabilidade, estimulando a crítica dos alunos, sem negar ou discriminar seu conhecimento e cultura.

Para os educadores, a dança sofre uma deturpação muito grande na mídia. Os meios de comunicação só mostram o lado sensual da dança, que é o que os alunos assistem e aprendem em relação a ela. Por outro lado, há indícios de comprometimento na tentativa de realizar um trabalho diferenciado, visando a mudança do ensino da dança no cenário educativo.

Dentre as sugestóes indicadas pelos docentes participantes dessa pesquisa-ação, para amenizar os problemas levantados, consistiram no diálogo com os gestores escolares sobre a dança criativa, na elaboração do plano de ensino a ser realizado no decorrer do programa, como um trabalho de conclusão de curso (TCC), nas oficinas anuais, na constituição de um grupo de estudos permanente para produção de artigos, na continuação como extensão, na possibilidade do programa ser obrigatório e na participação dos PEF, PA e PP da mesma escola no programa. Essas sugestões tiveram uma indicação por docente.

O diálogo dos agentes formadores com os gestores escolares sobre a dança educativa foi uma sugestão da PP (EF) Olga, destacando que "o diálogo com as escolas participantes doprojeto [...] para que estas facilitem a execução das aulas de dança criativa", bem como "esclarecer aos gestores dos benefícios da dança na escola, para que promovam eestabeleçam uma ponte para um trabalho interdisciplinar". Essa sugestão pode ter sidoinfluenciada pela maneira como foi conduzido o programa, através da reflexão, colaboração e inovação, procurando sempre dialogar para superar as necessidades e solucionar os problemas, na busca de uma educação transformadora e do entendimento da importância da dança na escola.

A sugestão da PP (EI) Ruth é sobre a equipe gestora dos programas de formação continuada, vislumbrando mudanças na prática pedagógica, bem como fomentar a política de ensino nessa área de conhecimento e a 
possibilidade do programa ser obrigatório para todos os educadores, como podemos evidenciar no excerto a seguir

Após três semestres de curso, fica aqui uma inquietação, com as instâncias de coordenação, questões relacionadas à mudança de "olhar" neste caso, a dança criativa no contexto escolar. Neste sentido chegaremos de fato a resultados concretos de uma formação continuada, ou seja, a mudança de prática de professor, tendo como pano de fundo uma política que se mostre também, reflexo de uma contribuição dos professores. Uma vez que uma das propostas da formação continuada é a melhoria da finalidade de ensino. Gostaria muito de ver o caminho de volta, que o "produto" dessa formação fique garantido, seja de fato considerado e fomente uma política de ensino na sua respectiva área do conhecimento. (PP(EI) RUTH)

Aqui evidenciamos a cobrança da educadora por uma política pública de formação continuada, que auxilie o processo de mudança da prática pedagógica, em relação ao ensino da dança, no sentido de subsidiar todas as ações (estruturais, materiais, pedagógicas, etc.) necessárias para garantir que as contribuições dessa formação aconteçam de fato nas escolas.

A sugestão da PP (EF) Gabriela foi de realizar o "plano de ensino [...] no decorrer docurso (tipo um TCC) com tempo previsto para tal e com orientação. Para isso talvez o curso poderia ser quinzenal, já previsto esse tempo para a teoria sistematizada". Cabe ressaltarque, no $3^{\circ}$ módulo do programa, realizamos a sistematização do ensino da dança na escola, denotando o interesse em continuar estudando, pesquisando e analisando, para elaborar um plano de ensino com embasamento teórico e com a devida orientação.

A PP (EF) Mora indicou que "sejam pensadas e oferecidas algumas oficinas anuais,para que possamos ficar cada vez mais familiarizados com os conteúdos de dança e poder utilizá-los com frequência no processo ensinoaprendizagem". Enquanto a PA Nair sugeriuque após o término do programa "poderia ser constituido grupos para a elaboração deartigos, bem como agendar encontros uma vez por mês para a discussão dos textos e o compartilhar as experiências realizadas nas escolas".Já o PEF Julio mencionou que oprograma "continuasse como extensão, pós-graduação lato-sensu".

Por fim, a PP (EF) Roxane pediu que houvesse a "participação de todos os professoresda mesma escola no programa", o que faria com que houvesse uma maior interação entre oseducadores da mesma unidade escolar, bem como o reconhecimento da importância desse conteúdo no currículo, tornando mais fácil promover a interdisciplinaridade entre as áreas.

Notamos, por meio desses depoimentos, a necessidade de continuar buscando o conhecimento dos conteúdos da dança, seja através das oficinas anuais, grupos de estudos ou através de uma pós-graduação, demonstrando o comprometimento e engajamento com a qualidade do ensino da dança na escola.

Considerando a sugestão indicada por uma docente na pesquisa de doutorado (Sousa, 2016) sobre a participação da gestão no referido programa,vislumbrando mudanças na relação do gestor com as professoras no tocante a prática pedagógica, objetivou na investigação de pós-doutorado (Sousa \& Hunger, 2018) analisar a eficácia da pesquisa-ação de programa de formação continuada colaborativa em Educação Física, com foco no ensino da dança criativa (Laban, 1978, 1990) em duas instituições escolares (educação infantil e anos iniciais do ensino fundamental), promovido por uma Universidade Pública em parceria com a Secretaria Municipal de Educação de uma cidade do interior paulista.

Os participantes da equipe escolar (professores, direção, coordenação) manifestaram que o estudo e as experiências dançantes articuladas teoricamente com os elementos coreológicos da dança criativa de Laban $(1978,1990)$ foram sempre enriquecedores, inovadores e muito importantes para que pudessem refletir sobre a realidade da dança no referido sistema municipal de ensino. Também puderam trocar experiências, compartilhar os pontos positivos, limitações do trabalho e realizar adaptações para atender as necessidades de cada turma. O grupo sentiu a necessidade de ter um olhar diferenciado sobre o desenvolvimento da criança de acordo com a proposta pedagógica do município, além de perceber que são destinados poucos momentos para estimular as capacidades imaginativa e criativa. Por fim, salientaram a necessidade de discutir a sistematização da dança juntamente com a análise do projeto político-pedagógico da escola (Sousa \& Hunger, 2018). 
Sousa e Hunger (2018) concluíram que o programa permitiu a equipe escolar apropriar-se dos referidos conhecimentos, (re) construir um olhar diferenciado em relação à dança, compreendendo-a como linguagem, desenvolver segurança para ministrar esse conteúdo e sistematizar o processo de ensino-aprendizagem com a definição de objetivos, conteúdos, estratégias, procedimentos e avaliação.

Percebemos que esse grupo não teve problemas com os enfrentamentos internos, porque a gestão participou ativamente do programa, na qual providenciou tudo o que foi solicitado pelas docentes para ministrar os conteúdos de dança na escola. Notamos ainda, que o programa corrobora para amenizar as dificuldades relacionadas à formação e aos conhecimentos científico-metodológicos e as influências externas.

\section{Conclusões}

Em pleno século XXI, os enfrentamentos e barreiras a serem transpostos para ministrar os conteúdos de dança retratam uma educação escolar brasileira desafiante, currículos acadêmicos que não têm correspondido às reais necessidades dos docentes e estudantes, estrutura curricular engessada e disciplinas totalmente segregadas, acarretando formação e intervenção profissionais que privilegiam a hegemonia de determinados conteúdos nas áreas de Educação Física (esporte), na Arte (artes visuais) e na Pedagogia (português e matemática), em detrimento de outros e, no caso do nosso estudo, da dança. No entanto, faz-se necessário oportunizar currículos escolares que apresentem propostas engajadas com a redução das desigualdades sociais, oferecendo, para os sujeitos inseridos no processo educativo, experiências corporais, artísticas, cognitivas, sociais e culturais.

A dança faz parte da cultura e é um conteúdo riquíssimo a ser trabalhado no contexto escolar. O ambiente, reconhecido como um espaço de transformações sociais, promove a produção de conhecimento e a valorização de diversas culturas, por meio de uma leitura crítica de mundo.

Ao comparar os resultados da presente pesquisa com outros estudos, consideramos inadmissível que os enfrentamentos e barreiras, em relação ao ensino da dança na escola, manifestados pelo grupo de professores colaboradores de Educação Física, Arte e Pedagogia, sejam os mesmos há décadas, apesar das transformações(globalização, revolução tecnológica e de comunicação, formação de blocos econômicos, organização do mundo do trabalho, etc) ocorridas na sociedade e na educação. Por isso, a importância de se compreender a educação na dinâmica das transformações do movimento político, econômico, cultural e social, ocorridas de forma globalizada e que devem ser enfrentadas pela sociedade contemporânea.

Em relação aos enfrentamentos internos, os professores manifestaram as seguintes barreiras: materiais didático-pedagógicos, infraestrutura escolar, equipe escolar eresistência dos alunos. O principal enfrentamento para ministrar os conteúdos de dança, relatado pelos professores, é referente aos materiais didático-pedagógicos disponíveis na escola. Essa evidência demonstra que as escolas apresentam carência e burocracia, da parte da equipe gestora e órgãos públicos, para acessar tais materiais, o que prejudica a atuação e a prática pedagógica dos professores.

Na tentativa de enfrentar esse problema, Peres, Ribeiro e Martins (2001) sugerem a busca de cursos, livros e bibliografias, como desenvolvimento de estratégias para a produção do conhecimento em dança. Já Diniz e Darido (2012) apresentam a proposta de um livro didático voltado para a articulação entre Educação Física, Pluralidade Cultural e Dança.

Hunger et al. (2014) salientam que houve aumento de produções acadêmicas e livros, entre outros materiais referentes aos estudos, sobre a dança na escola. Contudo, essa literatura não chega às escolas, dificultando o acesso do professor a informações que auxiliam no planejamento das suas aulas e amenizam suas dificuldades.

As iniciativas são muito importantes e por isso acreditamos que o poder público precisa fazer os investimentos necessários para suprir a deficiência de materiais didático-pedagógicos e dar o suporte adequado para o trabalho docente em relação à dança. 
A segunda barreira abordada pelos docentes destaca a falta de infraestrutura escolar, como limitação do espaço, estrutura física inadequada e falta de espaço físico. Os prédios escolares são elementos importantes no quesito qualidade da educação, embora, os projetos de grande parte das escolas apresentem uma arquitetura tradicional e continuem a ser uma tendência predominante na primeira década do século XXI.

Cabe salientar que os prédios escolares devem estar adequados às novas realidades e necessidades educacionais e de ensino, ou seja, serem flexíveis e adaptáveis às mudanças (sociais, culturais, econômicas, políticas), para proporcionar espaços diferenciados e mais adequados à aprendizagem. Esse é o grande desafio a ser enfrentado pelas políticas educacionais.

Gaspari (2011) e Saraiva et al. (2005) sugerem que os professores utilizem outros espaços escolares, com o intuito de oportunizar as vivências em dança em diferentes lugares na escola, porém a equipe escolar também precisa pensar, discutir e refletir sobre a organização espacial e temporal (Sousa, Hunger, \& Caramaschi, 2014) disponíveis na escola, para que todos os professores possam ministrar qualquer conteúdo aos alunos.

A terceira barreira citada pelos professores aponta para a falta de apoio da equipe escolar, no desenvolvimento de atividades diversificadas, como é o caso da dança, que pode atrapalhar o andamento das demais aulas, devido ao barulho e à visão de ensino tradicional. Faz-se necessária a aproximação de todos os envolvidos no processo educativo, para que adquiram um olhar mais amplo do ensino da dança.

Marques (2011) salienta que, ao pensar na dança educativa, estejamos preparados para partir da realidade e do contexto nos quais o aluno está inserido, para então, transformarmos, de forma consciente, o conteúdo a ser ensinado. Assim, levaremos o aluno a pensar na dança como um processo individual, coletivo e social, em que todos são produtores de saberes e conhecimentos.

A resistência dos alunos foi o quarto enfrentamento destacado pelos docentes. Essa questão está presente no contexto escolar e é importante proporcionar experiências dançantes na escola, por meio de prática lúdica, divertida e prazerosa, oportunizando discussões entre dança e gênero, visando estimular as interações sociais (Saraiva-Kunz, 2003) e mostrando que todos podem e têm o direito de dançar. Marques (2012) ressalta que a dança na escola deve ser capaz de possibilitar ao aluno conhecer-se, conhecer os outros e inserir-se no mundo de modo comprometido e crítico.

No tocante à formação e aos conhecimentos científico-metodológicos, destacaram-se a falta de capacitação, o conbecimento específico em dança e os procedimentos didático-pedagógicos. Essa constatação é preocupante, porque, após décadas de discussões e produção de conhecimentos, principalmente na Educação Física, ainda percebemos que as graduaçóes, nessa área, não conseguiram estruturar as disciplinas voltadas para os conteúdos de dança e não foram suficientes para subsidiar a prática pedagógica dos professores.

As lacunas existentes podem ser amenizadas através da união dessas licenciaturas, para um repensar globalizante do ensino da dança na escola, em prol de uma construção curricular entrelaçada com os ideais de desenvolvimento integrado, possibilitando discutir e refletir sobre as especificidades e convergências de cada área, para a viabilização de um trabalho coletivo das instituições formadoras.

As pesquisas que abordam a inserção da dança no contexto escolar brasileiro reconhecem a importância e a riqueza dessa manifestação. A inclusão da dança nos componentes curriculares da Arte e da Educação Física está nos documentos oficiais (DCNGEB, 2013; PCN, 1997a, 1997b, 1997c; RCNEI, 1998; Resolução, 2009; Resolução, 2010), nas propostas curriculares de municípios e estados, bem como na BNCC (2017), que visa orientar a elaboração de currículos para as diferentes etapas de escolarização, em todo o território nacional.

Entretanto, ainda não houve plena apropriação da proposta curricular por esses docentes, no sentido de estarem familiarizados com o discurso oficial, em suas práticas no ambiente escolar. É importante que os professores e equipe escolar tenham consciência de que esses documentos precisam constantemente de reflexão e atualização, pois um profissional desatualizado, que apresenta formação profissional insuficiente e com certas deficiências, terá sua prática pedagógica comprometida. Faz-se necessário o engajamento 
e a participação dos professores e equipe escolar nos projetos, para que as políticas educacionais sejam transformadoras.

Quanto às interferências externas, a religião e a mídia são duas barreiras que precisam ser enfrentadas com muita atenção e prudência. Uma possibilidade para abordar a religião é promover encontros com os pais, professores e equipe gestora, para esclarecer o objetivo da dança na escola, apresentando os conteúdos que serão desenvolvidos, de modo a deixar claro o embasamento teórico-prático adotado, sobretudo na compreensão das relações entre o conhecimento da dança com os sujeitos e com a sociedade, na construção de sentido e significado, nos processos de ensino-aprendizagem de dança (Marques, 2011, 2012).

Já a mídia é um poderoso meio de comunicação, que interfere no processo de educação e, consequentemente, no modo como as crianças dançam. As canções acabam influenciando e até refletindo negativamente na vida da criança, provocando e estimulando a sexualização precoce, trazendo prejuízos imediatos ao aprendizado da criança (Sborquia \& Galhardo, 2002), sobretudo na identidade e significado do corpo.

Sborquia e Gallardo (2002) acrescentam que as danças da mídia não possuem nenhuma intenção de arte, visando apenas as demandas de mercado e que a escola muitas vezes reproduz o que a mídia impóe ou nega esse fato. Entretanto, acreditamos que essa é mais uma barreira a ser enfrentada pela comunidade escolar, no intuito de estimular debates sobre os conteúdos de dança na escola, que promovam a consciência crítica dos alunos.

Em menor ou maior grau, são muitas as barreiras que enfrentam os PEF, PA e PP. Não basta ter o conhecimento sobre o ensino da dança, o docente tem que vencer os desafios diários que surgem no cotidiano escolar. Por isso, ressal tamos a necessidade de dialogar, discutir e refletir com toda equipe escolar, os enfrentamentos e barreiras a serem transpostos no ensino da dança na escola, para pensarem conjuntamente possíveis soluções sobre as questões relacionadas com a aquisição de materiais didático-pedagógicos, a organização dos espaços escolares, bem como a explicação para a comunidade escolar sobre os objetivos da dança na escola.

Sousa e Hunger (2018) constataram que o programa de formação continuada em Educação Física, com foco na dança criativa, realizada na escola envolvendo toda equipe fomentou uma possibilidade de mudança da prática pedagógica e da proposta educacional de maneira autônoma, criativa, inovadora e colaborativa. E o referencial teórico eleito nesta pesquisa permitiu avançar na produção do conhecimento em relação à temática, compreender o processo de reconstrução da realidade cultural escolar e as relações estabelecidas entre todos os atores educacionais e, consequentemente uma atuação profissional consciente do seu papel na sociedade.

Enfim, urge rever os projetos político-pedagógicos, sobretudo, numa tomada de decisão da equipe escolar para reconhecer o significado do ensino e da aprendizagem da dança na formação integral e diferenciada do educando e melhorar a prática pedagógica dos professores.

\section{Agradecimentos}

Fundação de Amparo à Pesquisa do Estado de São Paulo (FAPESP); CNPq -Pós-Doutorado Júnior (PDJ);CNPq - Produtividade em Pesquisa - PQ, nível 2.

\section{REFERÊNCIAS}

Ministério da Educação e Cultura (BR). Secretaria de Educação Fundamental. Parâmetros Curriculares Nacionais: introdução aos parâmetros curriculares nacionais. Brasília: MEC/SEF; 1997.

Ministério da Educação e do Desporto (BR). Secretaria de Educação Fundamental. Referencial curricular nacional para a educação infantil. Brasília: MEC/SEF; 1998. 
Conselho Nacional de Educação (BR). Câmara de Educação Básica. Resolução CNE/CEB nº 5, de 17 de dezembro de 2009. Fixa as Diretrizes Curriculares Nacionais para a Educação Infantil. Brasília: MEC, SEB; 2009.

Conselho Nacional de Educação (BR). Câmara de Educação Básica. Resolução CNE/CEB no 7, de 14 de dezembro de 2010. Fixa Diretrizes Curriculares Nacionais para o Ensino Fundamental de 9 (nove) anos. Brasília: MEC, SEB; 2010.

Ministério da Educação (BR). Secretaria de Educação Básica. Diretrizes Curriculares Nacionais Gerais da Educação Básica. Brasília: MEC, SEB, DICEI; 2013.

Ministério da Educação (BR). Secretaria de Educação Básica. Base Nacional Comum curricular: educação é a base. Brasília: MEC, SEB, DICEI; 2017

Bardin, L. (2016). Análise de conteúdo (Ed. rev.). Lisboa: Edições 70.

Barreto, D. (2004). Dança... ensino, sentidos e possibilidades na escola. Campinas: Autores Associados.

Bogdan, R., \& Biklen, S. (2013). Investigação qualitativa em educação: uma introdução à teoria e aos métodos (12a. ed.). Porto: Porto Editora.

Böhm, N. V. S., \& Toigo, A. M. (2012). A dança nas aulas de educação física: a visão de alunos e professores das $5^{\text {a }}$ e $6^{a}$ séries de uma escola municipal de Canoas, RS. CIPPUS - Revista de Iniciação Científica, 1(2), 158-159. Recuperado de https://revistas.unilasalle.edu.br/index.php/Cippus/article/view/315/685

Brasileiro, L. T. (2002). O conhecimento no currículo escolar: o conteúdo dança em aulas de Educação Física na perspectiva crítica. Movimento, 8(3), 5-118. Recuperado de http://www.seer.ufrgs.br/index.php/Movimento/a rticle/view/2646/1272. doi: http://dx.doi.org/10.22456/1982-8918.2646.

Brasileiro, L. T. (2008). O ensino da dança na Educação Física: formação e intervenção pedagógica em discussão. Motriz, 14(4), 519-528. Recuperado de http://www.periodicos.rc.biblioteca.unesp.br/index.php/motriz/articl e/view/2140/1912

Brasília, Ministério da Educação e Cultura, Secretaria de Educação Básica (2017). Base Nacional Común Curricular: Educação éa Base.

Brasília, Ministério da Educação e Cultura, Secretaria de Educação Básica (2013). Diretrizes Curriculares Nacionais Gerais da Educação Básica.

Brasília, Ministério da Educação e Cultura, Secretaria de Educação Fundamental (1997a) Parâmetros Curriculares Nacionais: Introdução aos Parâmetros Curriculares Nacionais.

Brasília, Ministério da Educação e Cultura, Secretaria de Educação Fundamental (1997b). Parâmetros Curriculares Nacionais: Arte.

Brasília, Ministério da Educação e Cultura, Secretaria de Educação Fundamental (1997c). Parâmetros Curriculares Nacionais: Educação Física.

Brasília, Ministério da Educação e Cultura, Secretaria de Educação Fundamental (1998). Referencial Curricular Nacional para a Educação Infantil.

Brasília, Conselho Nacional de Educação, Câmara de Educação Básica (2009). Resolução CNE/CEB no 5, de 17 de dezembro de 2009. (18 de dezembro). Fixa as Diretrizes Curriculares Nacionais para a Educação Infantil. Diário Oficial da União, Seção 1.

Brasília, Conselho Nacional de Educação, Câmara de Educação Básica (2010). Resolução CNE/CEB no 7, de 14 de dezembro de 2010. (15 dezembro). Fixa Diretrizes Curriculares Nacionais para o Ensino Fundamental de 9 (nove) anos. Diário Oficial da União, Seção 1.

Castro, V. G., Silva, D. S., \& Júlio, M. G. (2010). O preconceito da dança nas escolas. Lecturas: Educación Física y Deportes, 15(150), 1. Recuperado de http://www.efdeportes.com/efd150/o-preconceito-da-danca-nas-escolas htm 
Correia, M. M. (2006). Incluindo a dança nas aulas de Educação Física. Anais do X Encontro Fluminense de Educação Física escolar, Niterói, Rio de Janeiro, Brasil. Recuperado de http://www.uff.br/gef/logo-pos-grad_enfefe.htm

Cunha, J. M. J. (2012). Ensino de Artes: dificuldades, experiências e desafios. Revela Periódico de Divulgação Cientifica da FALS, 6(14), 1-20. Recuperado de http://fals.com.br/novofals/revela/REVELA\%20XVII/art_exp05_14.p $\mathrm{df}$

Denzin, N. K., \& Lincoln, Y. S. (2006). O planejamento da pesquisa qualitativa: teorias e abordagens (2a. ed.). Porto Alegre: Artmed.

Diniz, I. K. S., \& Darido, S. C. (2012). Livro didático: uma ferramenta possível de trabalho com a dança na Educação Física Escolar. Motriz, 18(1), 176-185. Recuperado de http://www.scielo.br/pdf/motriz/v18n1/v18n1a18.pdf

Franco, M. A. S. (2005). Apresentação. Educação e Pesquisa, 31(3), 439-441. Recuperado de http://www.revistas.us p.br/ep/article/view/27988/29769

Gasparelo, A. C., Kronbauer, G. A., \& Gomes, D. (2018). Arte e educação física: o caso da dança na escola. EDUCA - Revista Multidisciplinar em Educação, 5(10), 30-49. Recuperado de http://www.periodicos.unir.br/index.php /EDUCA/index. e-ISSN: 2359-2087

Gaspari, T.C. (2005).Educação Fisica escolar e dança: uma proposta de intervenção (Tese de mestrado inédita). Instituto de Biociências, Universidade Estadual Paulista, Rio Claro, Brasil.

Gaspari, T. C. (2011). Dança. In S. C. Darido \& I. C. A. Rangel (Ed.). Educação física na escola: implicações para a prática pedagógica (pp. 201-228). Rio de Janeiro: Guanabara Koogan.

Gaspari, T. C., Souza, O.,Maciel Jr, V., Impolcefto, F., Venancio, L., \& Rosário, L. F. (2006). A realidade dos professores de educação física na escola: suas dificuldades e sugestões. Revista Mineira de Educação Física, 14(1), 109-137. Recuperado de http://www.mediafire.com/file/k4rkckznr6dz04w/A_realidade_dos_professores_de_Educa\% C3\%A7\%C3\%A3o_f\%C3\%ADsica_na_escola.pdf

Gil, A. C. (2009). Métodos e técnicas de pesquisa social (6a. ed.). São Paulo: Atlas.

Howe, K. R. (1988). Against the quantitative-qualitative incompatibility thesis - ordogmas die hard. EducationalResearcher. 17(8), 10-16. Recuperado de http://journals.sagepub.com/doi/pdf/10.3102/0013189 X017008010. doi: http://10.3102/0013189x017008010

Hunger, D., Rodrigues, R. N., Cunha, L. D., Santos, F. M., Bortoloti, B., \& Sousa, N. C. P. (2014). Programa de formação continuada em dança educativa. In L. D. Colvara \&J. B. B. Oliveira (Eds.). Núcleos de Ensino da Unesp: artigos 2012 (pp. 209-234). São Paulo: Cultura Acadêmica: Universidade Estadual Paulista.

Imbernón, F. (2010). Formação docente e profissional: formar-se para a mudança e a incerteza (8a. ed.). São Paulo: Cortez.

Johnson, R. B., Onwuegbuzie, A. J, \& Turner, L. A. (2007). Toward a definition of mixed method research. Journal of Mixed Methods Research, 1(2), 112-133. Recuperado de http://journals.sagepub.com/doi/abs/10.1177/1558 689806298224. doi: http://10.1177/1558689806298224.

Laban, R. (1978). Dominio do Movimento. São Paulo: Summus.

Laban, R. (1990). Dança educativa moderna. São Paulo: Ícone.

Lessa, M. M. F. L., \& Lima, P. R. F. (2014). Dança na educação física: as dificuldades do ensino nas escolas públicas de Canindé-CE. FIEP BULLETIN, 84(n. ${ }^{\circ}$ esp.), 1-6. Recuperado de http://www.fiepbulletin.net/index.php/ fiepbulletin/article/view/4366/8541

Marques, I. A. (2011). Ensino de dança hoje: textos e contextos (6a. ed.). São Paulo: Cortez.

Marques, I. A. (2012). Dançando na escola (6a. ed.). São Paulo: Cortez.

Mizukami, M. G.N., \& Reali, A. M. M. R. (2002). Formação de professores, práticas pedagógicas e escola. São Carlos: EdUFSCar.

Morandi, C. (2006). O ensino de dança nas escolas: introdução. In M. Strazzacappa, \& C. Morandi (Orgs.). Entre a arte e a docência:formação do artista da dança (pp. 71-76). Campinas: Papirus. 
Peres, A. T., Ribeiro, D. M. D. B., \& Martins, J. M., Jr. (2001). A dança escolar de $1^{\circ}$ a $4^{\circ}$ série na visão dos professores de Educação Física das escolas estaduais de Maringá. Revista Educação Física UEM, 12(1), 19-26. Recuperado de http://www.periodicos.uem.br/ojs/index.php/RevEducFis/article/view/3760

Pereira, M. L. (2007). A formação acadêmica do professor de Educação Física:em questão o conteúdo da Dança. (Tese de mestrado inédita). Instituto de Biociências, Universidade Estadual Paulista, Rio Claro, Brasil.

Rossi, F. (2013). Implicações da formação continuada na prática pedagógica do(a) professor(a) noâmbito da cultura corporal de movimento. (Tese de doutorado). Instituto de Biociências, Universidade Estadual Paulista, Rio Claro, Brasil.

Saraiva-Kunz, M. C. (2003). Dança e gênero na escola: formas de ser e viver mediados pela educação estética (Tese de doutorado). Faculdade de Motricidade Humana, Universidade Técnica de Lisboa, Lisboa, Portugal.

Saraiva-Kunz, M. C. (2004). Investigando dança e gênero na escola: uma abordagem fenomenológica. Estudos de dança, $8(57), 135-146$.

Saraiva, M. C., Fiamoncini, L., Abrão, E., \& Krischke, A. A. (2005). Dança e seus elementos constituintes: uma experiência contemporânea. In A. M. Silva \& I. R. Damiani (Eds.). Práticas Corporais: experiências em educação fisica para uma formação humana. (pp. 115-133). Florianópolis: Nauemblu Ciência e Arte.

Saraiva, M. C., \& Fiamoncini, L. (2013). Dança na escola: a criação e a co-educação em pauta. In E. Kunz (Ed.). Didática da Educação Física 1 (pp. 95-120). Ijuí: Unijuí.

Sborquia, S. P., \& Gallardo, J. S. P. (2002). As danças na mídia e as danças na escola. Revista Brasileira de Ciências do Esporte, 23(2), 105-118. Recuperado de http://revista.cbce.org.br/index.php/RBCE/article/view/273/256

Scarpato, M. T. (2004). A formação do professor de educação física e suas experiências com a dança. In: E. C. Moreira (Org.). Educação física escolar:desafios e propostas (pp. 65-73). Jundiaí: Fontoura.

Sgarbi, F. (2009). Entrando na dança: reflexos de um curso de formação continuada para professores de educação infantil (Tese de mestrado inédita). Instituto de Artes, Universidade Estadual Paulista, São Paulo, Brasil.

Silva, W. F., Alves, D. S., \& Ribeiro, G. F. F. (2010). Aplicabilidade do conteúdo dança nas escolas da rede estadual de ensino fundamental na cidade de Porteirinha, MG. Lecturas: Educación Fisica y Deportes, 15(149), 1. Recuperado de http://www.efdeportes.com/efd149/aplicabilidade-do-conteudo-danca-nas-escolas.htm

Sousa, N. C. P. (2016). Pesquisa-ação de formação continuada em Educação fisica no âmbito da dança: as possiveis implicaçôes no repensar e na transformação da prática pedagógica de Educação física, Arte e Pedagogia. (Tese de doutorado). Instituto de Biociências, Universidade Estadual Paulista, Rio Claro, Brasil.

Sousa, N. C. P., Hunger, D. A. C. F., \& Caramaschi, S. (2010). A dança na escola: um sério problema a ser resolvido. Motriz, 16(2), 496-505. Recuperado de https://repositorio.unesp.br/bitstream/handle/11449/8356/WOS00 0284782500024.pdf?sequence $=3$

Sousa, N. C. P., Hunger, D. A. C. F., \& Caramaschi, S. (2014). O ensino da dança na escola na ótica dos professores de Educação Física e de Arte. Revista Brasileira de Educação Física e Esporte, 28(3), 505-520. Recuperado de htt p://www.scielo.br/pdf/rbefe/v28n3/1807-5509-rbefe-28-03-00505.pdf. doi: http://dx.doi.org/10.1590/1807 $-55092014000300505$

Sousa, N. C. P., \& Hunger, D. (novembro de 2018). Formação continuada em dança criativa de Laban:realidade e possibilidade de mudança na escola. Trabalho apresentado no XI Congresso Nacional de Educação Física e XXII Reunião Científica: Práticas que transformam: um papel da educação física. Conef/Unesp. Bauru, São Paulo. Resumo recuperado de: https://drive.google.com/file/d/1jL2MtciYvfdD7p3tH38FXNWk9WmC28SI/view

Strazzacappa, M. (2003). Dança na educação: discutindo questões básicas e polêmicas. Pensar a Prática, 6, 73-85. Recuperado de https://www.revistas.ufg.br/fef/article/view/55

Strazzacappa, M., \& Morandi, C. (2006). Entre a arte e a docência:formação do artista da dança. Campinas: Papirus

Thiollent, M. (2011). Metodologia da pesquisa-ação (18a. ed.). São Paulo: Cortez. 